\title{
PEMANFAATAN POWTOON SEBAGAI SALAH SATU ALTERNATIF MEDIA DALAM PEMBELAJARAN DARING DI SDN II KEDUNGDAWA CIREBON
}

\author{
Setiyani ${ }^{1}$, Dina Pratiwi Dwi Santi2), Ferry Ferdianto ${ }^{1)}$ \\ 1)Pendidikan Matematika, FKIP, Universitas Swadaya Gunung Jati, Cirebon, Jawa Barat, Indonesia \\ 2)Pendidikan Guru Sekolah Dasar, FKIP, Universitas Swadaya Gunung Jati, Cirebon, Jawa Barat, Indonesia \\ Corresponding author : Setiyani \\ E-mail : setiyani_0401509081@yahoo.com
}

Diterima 23 September 2020, Direvisi 15 Oktober 2020, Disetujui 15 Oktober 2020

\begin{abstract}
ABSTRAK
Masa pandemi covid 19 telah mengganggu proses belajar tatap muka di sekolah. Pembelajaran Jarak Jauh (PJJ) secara daring menjadi salah satu alternatif untuk mengatasi masalah tersebut. Oleh karena itu perlu peranan media agar siswa tidak jenuh dalam belajar. Tujuan kegiatan pengabdian kepada masyarakat (PKM) ini adalah menerapkan powtoon sebagai salah satu alternatif media dalam PJJ di SDN II Kedungdawa Kabupaten Cirebon. Kegiatan PKM dilakukan dengan harapan guru termotivasi mengintegrasikan IT secara maksimal untuk membuat video pembelajaran yang dapat digunakan dalam proses belajar. Metode dalam kegiatan PKM terdiri dari 4 tahap yaitu observasi, identifikasi masalah, solusi, dan evaluasi. Peserta dalam pengabdian ini sebanyak 28 siswa kelas VI. Hasil pemanfaatan media powtoon diantaranya meningkatkan motivasi siswa, pembelajaran tidak membosankan, dan materi lebih mudah dipahami. Selain itu adanya ketertarikan guru untuk dapat membuat media powtoon sendiri merupakan salah satu indikator keberhasilan PKM yang telah dilakukan. Oleh karena itu sebagai rekomendasi tim akan merancang kegiatan pelatihan pembuatan powtoon yang menarik, variatif dan interaktif sebagai upaya peningkatan kualitas pembelajaran bagi guru di SDN II Kedungdawa Kabupaten Cirebon
\end{abstract}

Kata kunci: powtoon; pembelajaran jarak jauh; media pembelajaran.

\begin{abstract}
The Covid 19 pandemic has disrupted the face-to-face learning process in schools. Distance learning is an alternative to overcome this problem. Therefore we need the role of the media so that students are not bored in learning. The purpose of this community service activity is to implement the powtoon as an alternative media in distance learning at SDN II Kedungdawa, Cirebon Regency. PKM activities are carried out with the hope that teachers are motivated to optimally integrate IT to make learning videos that can be used in the learning process. The method in PKM activities consists of 4 stages, namely observation, problem identification, solution, and evaluation. Participants in this activities were 28 students in grade sixth.The results of using powtoon media include increasing student motivation, learning is not boring, and the material is easier to understand. In addition, the teacher's interest in being able to make their own powtoon media is an indicator of the success of the PKM that has been carried out. Therefore, as a recommendation, the team will design training activities for making powtoon that are interesting, varied and interactive as an effort to improve the quality of learning for teachers at SDN II Kedungdawa, Cirebon.
\end{abstract}

Keywords: powtoon; distance learning; material teaching.

\section{PENDAHULUAN}

Media pembelajaran merupakan salah

satu cara yang dapat mengarahkan perhatian dan merangsang pikiran siswa untuk merespons suatu pelajaran. Dalam proses belajar mengajar media digunakan dengan tujuan membantu guru agar proses belajar siswa lebih efektif dan efisien. Adanya media membuat hal-hal yang abstrak dapat disajikan dalam bentuk model-model berupa benda konkret yang dapat dilihat, dipegang, diputarbalikkan sehingga lebih mudah dipahami.

Pada masa pandemi ini, TIK berperan penting dalam Pembelajaran Jarak Jauh secara daring. Oleh karena itu banyak guru yang mengintegrasikan IT dalam proses pembelajaran karena banyak manfaatnya (Oktaviani et al., 2020) terutama untuk menunjang KBM secara daring. Banyak aplikasi edukasi yang dapat diakses gratis oleh pengajar. Oleh karena itu sangat disayangkan 
apabila maraknya aplikasi pembelajaran namun pemanfaatannya masih belum maksimal. Berdasarkan hasil studi pendahuluan tim Pengabdian Kepada Masyarakat (PKM) di SDN II Kedungdawa Kabupaten Cirebon, PJJ yang dilakukan guru kelas atau mata pelajaran melalui media whatssapp berupa tugas-tugas mandiri yang harus dikerjakan siswa. Selain itu siswa diminta untuk menyimak pembelajaran melalui media RCTV. Bukti fisik siswa belajar dirumah berupa foto yang dikirimkan melalui Whatsapp Group. Gambar 1 berikut adalah beberapa foto siswa sedang mengerjakan tugas yang diberikan oleh guru di rumah.

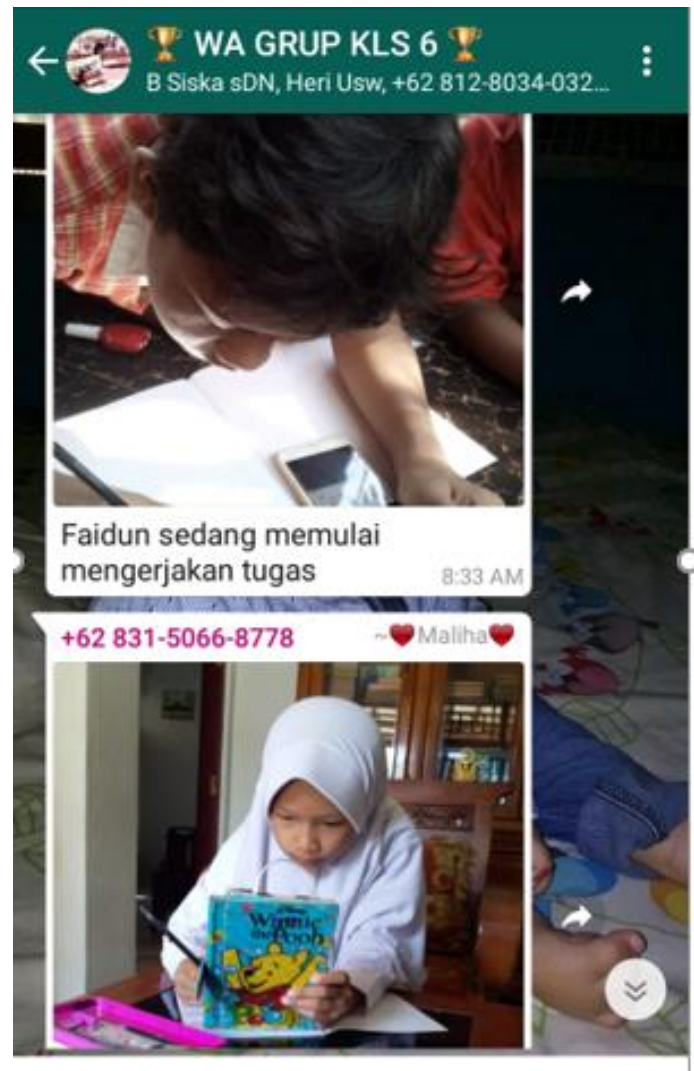

\section{Gambar 1. Pembelajaran Daring}

Pembelajaran seperti ini di duga cepat membuat siswa jenuh, apalagi belum ada kepastian kapan mereka akan berangkat sekolah. Oleh karena itu melalui kegiatan PKM ini, sekolah beserta tim akan menerapkan pembelajaran menggunakan media powtoon.

Pemilihan media powtoon diduga dapat menciptakan suasana pembelajaran yang menyenangkan dan membuat siswa tidak jenuh dengan materi yang disampaikan, karena media powtoon mempunyai fitur animasi yang menarik. Powtoon termasuk ke dalam perangkat lunak berbasis web. Powtoon ini hampir sama seperti powerpoint yang biasa digunakan untuk membuat media presentasi, cara kerjanya adalah dengan mengisi slide yang ada dengan materi presentasi kemudian slide yang berisi materi tersebut dikombinasikan dengan animasi dan efek transisi agar lebih menarik. Hasil akhir dari perangkat lunak ini berupa video, sehingga powtoon mampu mengatasi terbatasnya ruang, waktu, dan daya indra (Pais et al., 2017). Untuk menggunakan powtoon, pengguna harus membuat akun di situs powtoon (www.powtoon.com) atau login menggunakan salah satu profil media sosial pengguna yang ada (Kurniawati, 2020).

Pada media ini juga disajikan contoh soal mengenai materi yang diberikan serta latihan soal. Pemberian latihan soal ini bertujuan untuk menambah pengetahuan siswa dalam menggali informasi yang diperolehnya kemudian dituangkan dalam penyelesaian. Hasil akhir media ini berupa video yang dapat dijadikan sebagai sumber belajar dan dapat dipelajari dimana pun dan kapan pun. Oleh karena itu tujuan PKM ini adalah pemanfaatan powtoon sebagai salah satu alternatif media dalam PJJ di SDN II Kedungdawa Kabupaten Cirebon.

\section{METODE}

Berdasarkan permasalahan mitra PKM yaitu SDN II Kedungdawa Kabupaten Cirebon yang telah diuraikan pada bagian latar belakang, maka metode yang ditawarkan adalah pemanfaatan powtoon sebagai salah satu alternatif media dalam PJJ di SDN II Kedungdawa Kabupaten Cirebon. Pemanfaatan Powtoon sebagai media PJJ di SDN Kedungdawa II Kabupaten Cirebon dilaksanakan pada tanggal 25 Agustus 2020, melibatkan guru kelas VI serta siswa yang belajar secara daring sebanyak 28 orang. Pengabdian ini melalui 4 tahap dimulai dari proses observasi sampai dengan penentuan target luaran seperti terlihat pada gambar 2 berikut.

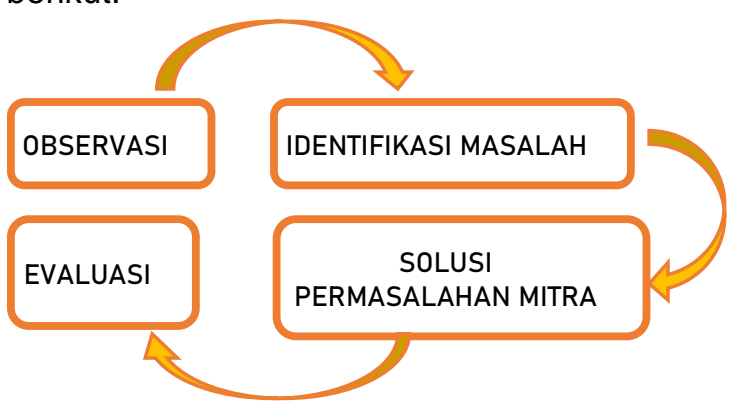

Gambar 2. Metode Pengabdian

\section{Tahap 1. Observasi}

Pada tahap observasi, tim melakukan wawancara tidak terstruktur dengan guru SDN II Kedungdawa terkait PJJ yang dilakukan selama masa pandemi. 
Tahap 2. Identifikasi Masalah

Pada tahap identifikasi Masalah, tim merumuskan masalah-masalah yang dialami mitra, membuat powtoon dengan topik pecahan pada pelajaran matematika dan menyusun angket respons siswa.

\section{Tahap 3. Solusi Permasalahan Mitra}

Pada tahap solusi permasalahan mitra, tim memberikan simulasi bagaimana memanfaatkan media powtoon pada PJJ di SDN II Kedungdawa Kabupaten Cirebon.

\section{Tahap 4. Evaluasi}

Pada tahap evaluasi, tim menganalisis angket respons siswa terhadap PJJ yang memanfaatkan Powtoon.

\section{HASIL DAN PEMBAHASAN}

Berdasarkan tahapan kegiatan yang telah diuraikan pada metode pelatihan, setelah tahap observasi dan identifikasi masalah maka tahap selanjutnya adalah implementasi kegiatan KBM dengan media Powtoon pada materi pecahan. Pada awal kegiatan pelatihan, tim menjelaskan tentang sekilas bagaimana membuat powtoon kepada guru kelas. Selanjutnya Tim meminta izin untuk bergabung dalam Whatssapp Group (WAG) untuk mengimplementasikan Powtoon pada saat jam pelajaran matematika. Durasi pembelajaran daring selama $2 \times 35$ menit yang terdiri dari pemaparan materi dan tanya jawab. Adapun pemaparan materi pecahan pada Powtoon yang diimplementasikan tampak pada gambar 3.

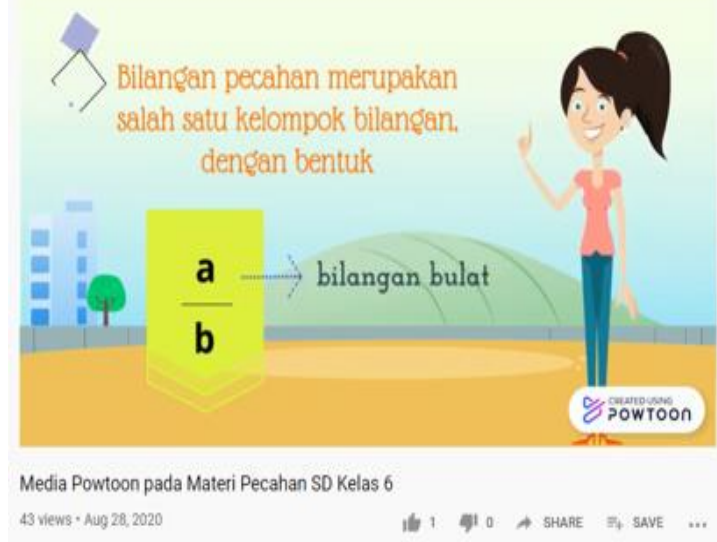

Gambar 3. Penjelasan Materi

Setelah pemaparan materi, siswa diberikan contoh soal mengerjakan pecahan pada penyebut yang sama dan berbeda, operasi penjumlahan dan pengurangan pecahan. Adapun salah satu contoh soal tampak pada gambar 4 berikut.

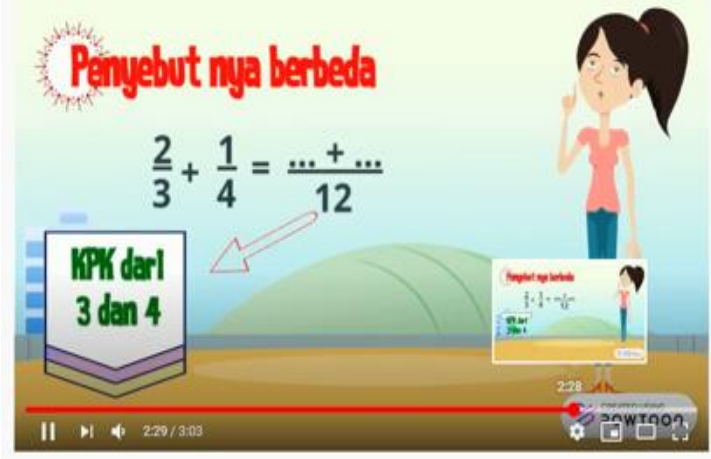

Media Powtoon pada Materi Pecahan SD Kelas 6

44 views - Aug 28, 2020

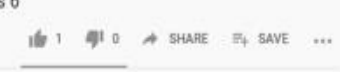

Gambar 4. Contoh Soal

Setelah anak-anak melihat video powtoon yang diunggah melalui You Tube, tim memberikan beberapa pertanyaan terkait pecahan melalui WAG. Pertanyaan yang diberikan tim dapat dilihat pada gambar 5 berikut.

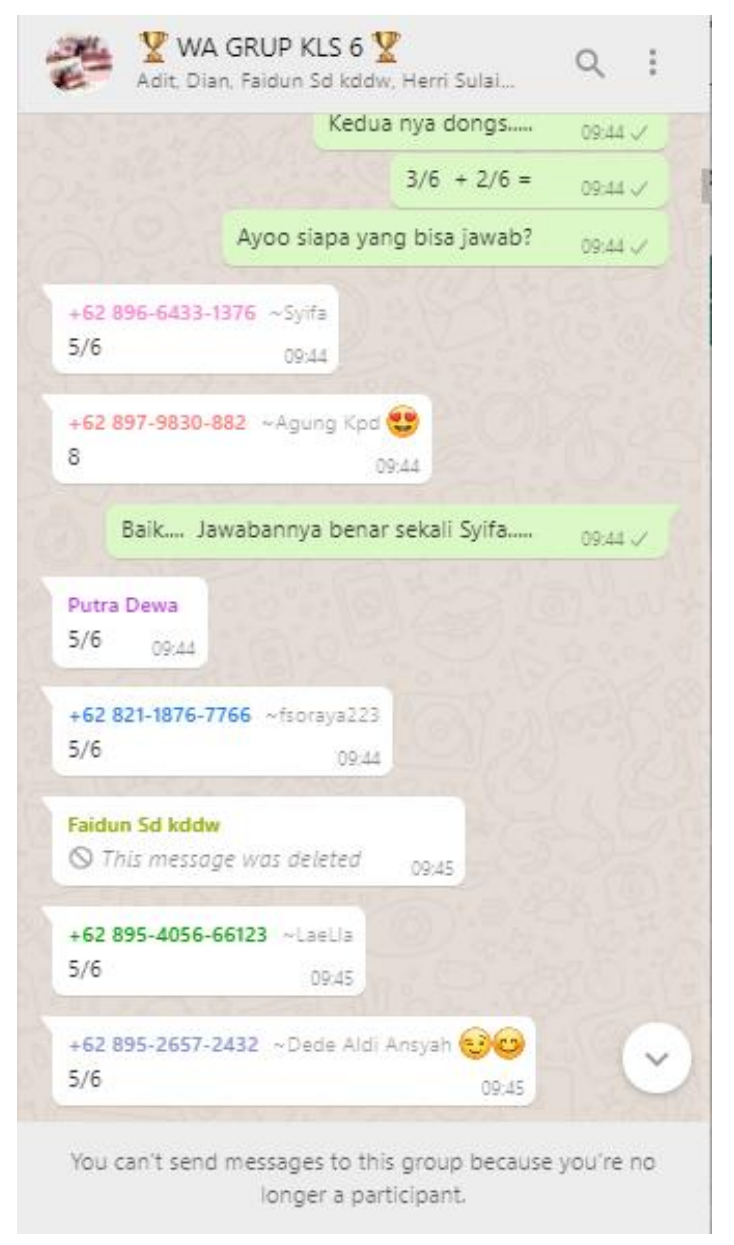

Gambar 5. Tanya Jawab Setelah Pembelajaran 
Walaupun dilakukan secara daring, namun anak-anak tetap aktif dan bersemangat dalam belajar. Setelah kegiatan pembelajaran secara daring, anak-anak diminta mengisi respons terhadap pembelajaran yang baru saja mereka alami. Angket respons diberikan melalui google form dan terdiri dari 10 pernyataan yang terdiri dari 4 jawaban yaitu sangat setuju, setuju, ragu-ragu, dan tidak setuju. Gambar 6 berikut ini adalah hasil rekapitulasi angket siswa pada setiap pernyataan terhadap media Powtoon.

Pada gambar 6 , sebagian besar siswa tidak setuju jika materi yang disampaikan menggunakan media powtoon sulit dipahami. Dengan kata lain siswa merasa lebih mudah memahami materi pecahan dengan media powtoon. Selain itu seluruh siswa menilai contoh soal yang diberikan telah sesuai dengan materi, sehingga siswa tidak merasa kesulitan dalam menjawab latihan soal. Hal ini sejalan dengan (Trina et al., 2017) bahwa sistem pembelajaran yang variatif menggunakan media animasi audio visual seperti powtoon akan membuat siswa lebih mudah dalam memahaminya.

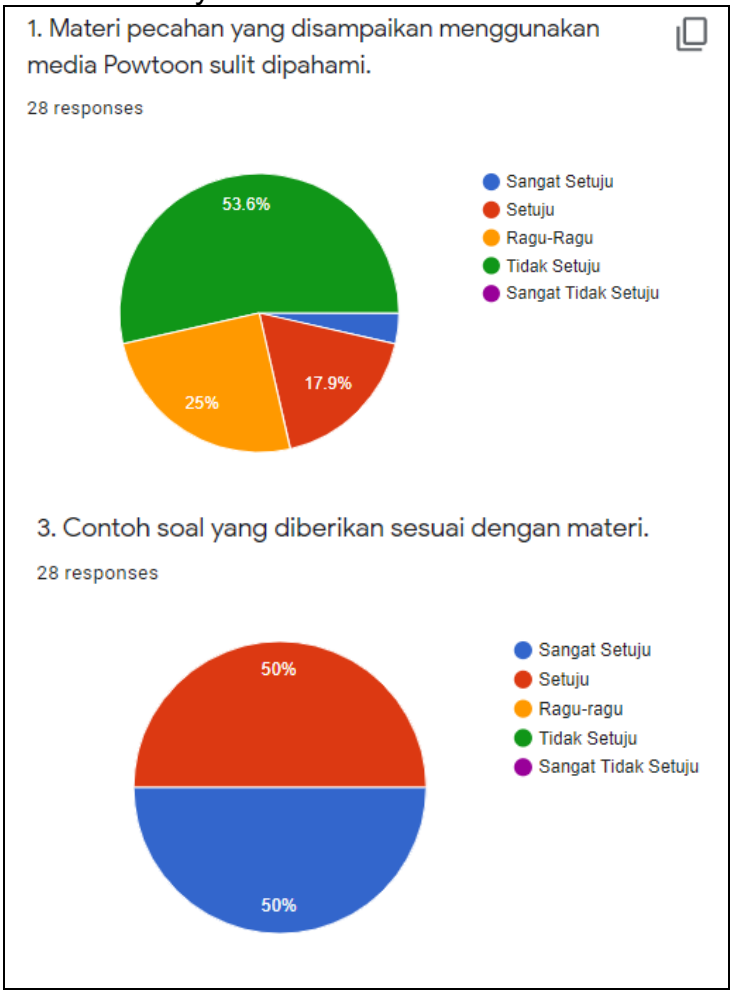

Gambar 6. Pemahaman Materi

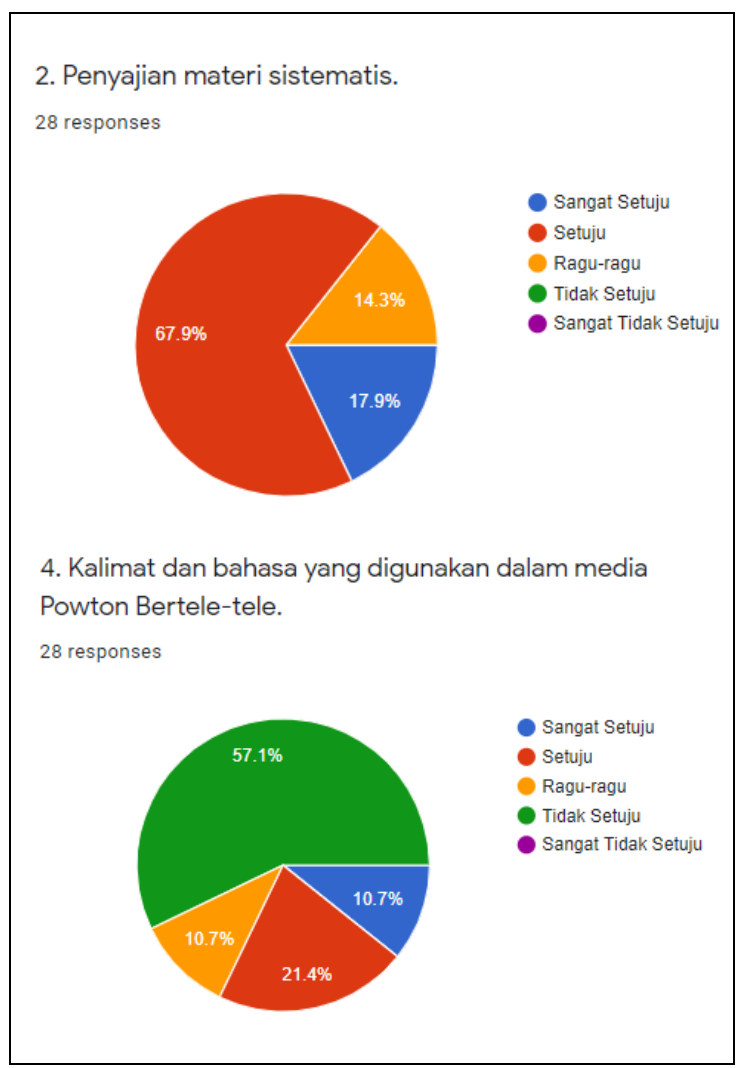

Gambar 7. Penyajian Materi

Pada gambar 7 , hampir seluruh siswa mengatakan bahwa materi yang disajikan melalui media powtoon sistematis, kalimat dan bahasa yang digunakan juga tidak berteletele.Pengaturan animasi pada media powtoon lebih mudah sehingga dapat disesuaikan dengan keinginan pengguna untuk memberikan ilustrasi terkait materi yang akan disajikan (Awalia et al., 2019). Hal ini sejalan dengan (Syafitri et al., 2018) bahwa powtoon memungkinkan guru dengan cepat dan mudah membuat persentasi animasi, memanipulasi objek yang telah dibuat sebelumnya, mengimpor gambar atau video sehingga pembelajaran menyenangkan bagi anak-anak.

Pada Gambar 8, Sebagian besar siswa menilai bahwa penyampaian materi tidak terlalu cepat dan setuju bahwa media powtoon menambah semangat dalam belajar matematika. Hal ini sejalan dengan (Pangestu \& Wafa, 2018) yang menyatakan bahwa media powtoon diharapkan dapat memotivasi siswa untuk aktif dalam KBM sehingga hasil belajar pun akan meningkat. Selain meningkatkan hasil belajar, powtoon juga meningkatkan keterampilan siswa dalam mengintegrasikan teknologi ke dalam ruang kelas virtual (Purnamasari et al., 2013). 
5. Media Powtoon menambah semangat saya dalam belajar matematika

28 responses

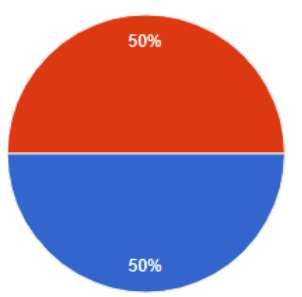

- Sangat Setuju

Setuju

Ragu-ragu

- Tidak Setuju

- Sangat Tidak Setuju

10. Penyampaian materi dalam media Powtoon terlalu cepat.

28 responses

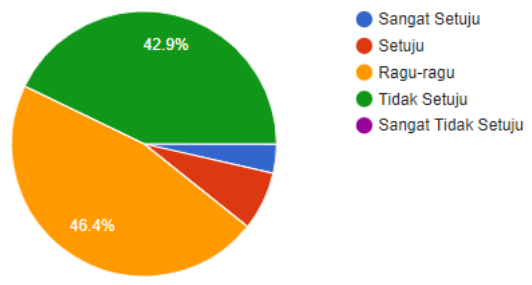

Gambar 8. Penyampaian Materi

6. Desain media Powtoon yang digunakan menarik.

28 responses

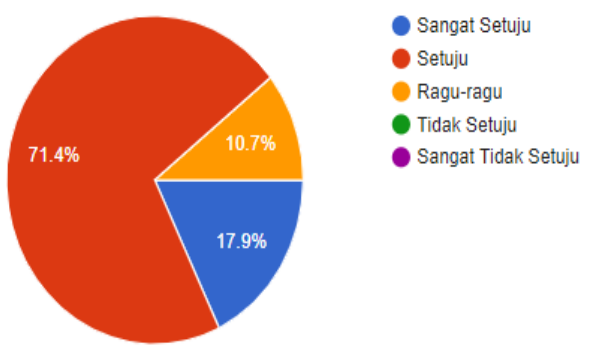

8. Bentuk, model, dan ukuran huruf yang digunakan sederhana dan mudah dibaca.

28 responses

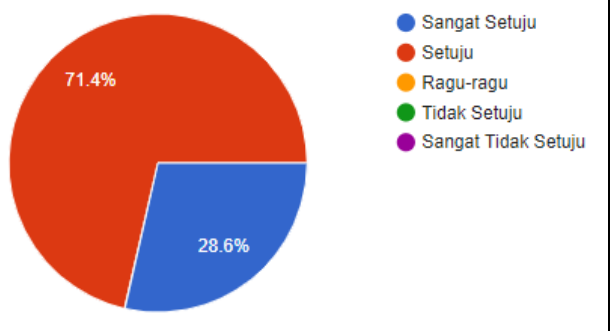

Gambar 9. Desain Powtoon

Pada gambar 9, seluruh siswa memberikan respons positif terhadap desain powtoon yang menarik, bentuk, model, dan ukuran huruf pada media powtoon sederhana dan mudah dibaca. Hal ini didukung oleh pernyataan (Nuswantoro \& Dwi Wicaksono, 2019) bahwa bentuk atau tampilan powtoon menarik dan terkesan lucu sehingga cocok untuk siswa sekolah dasar.

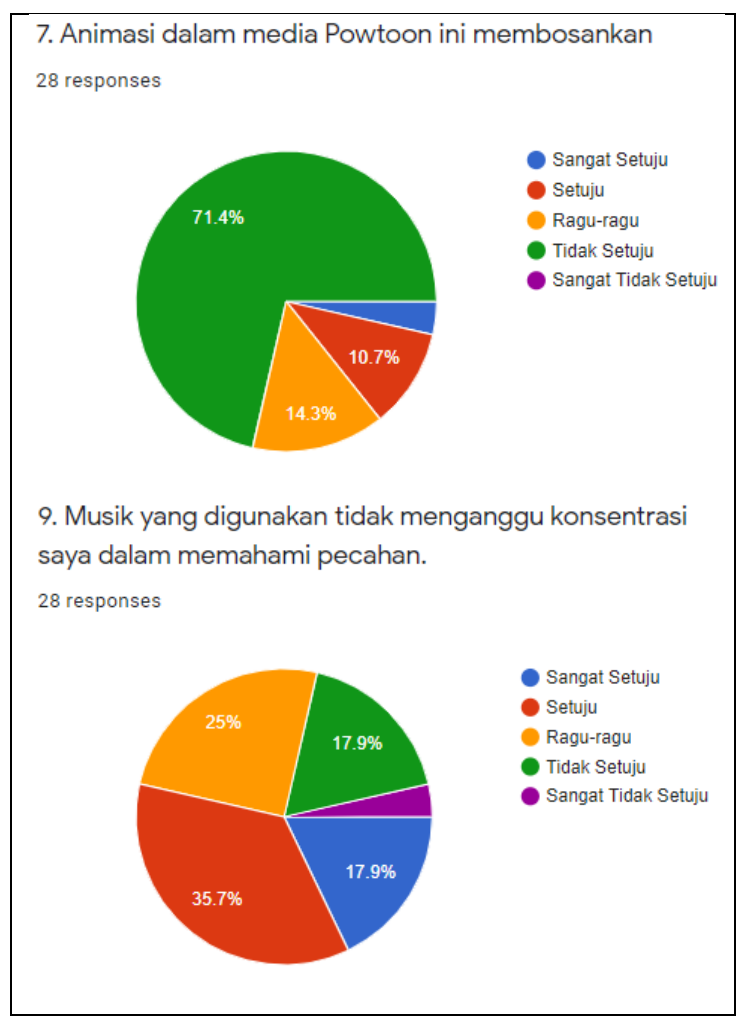

Gambar 10. Animasi Powtoon

Pada gambar 10 sebanyak $69 \%$ siswa tidak setuju jika animasi dalam media powtoon ini membosankan. Selanjutnya Sebagian besar siswa menilai musik yang digunakan tidak mengganggu konsentrasi dalam memahami materi. Powtoon memiliki beragam fitur animasi diantaranya kartun, tulisan tangan, musik, efek transisi yang lebih hidup dan time line yang mudah diatur memungkinkan materi disampaikan dengan menarik sehingga siswa tidak jenuh (Fitriyani, 2019).

\section{SIMPULAN DAN SARAN}

Pelaksanaan PKM pemanfaatan video pembelajaran di SDN II Kedungdawa Kabupaten Cirebon menggunakan powtoon berjalan sesuai dengan rencana. Beberapa indikator ketercapaian kegiatan PKM diantaranya adalah adanya respons positif siswa dalam melaksanakan PJJ dari rumah menggunakan media powtoon dan ketertarikan guru kelas untuk mempelajari bagaimana cara membuat powtoon. Oleh karena itu pada PKM selanjutnya, tim akan merancang kegiatan pelatihan pembuatan powtoon yang menarik, variatif dan interaktif sebagai upaya peningkatan kualitas pembelajaran. 


\section{UCAPAN TERIMAKASIH}

Tim PKM mengucapkan terimakasih kepada Lembaga Pengabdian Masyarakat (LPM) Univeritas Swadaya Gunung Jati yang telah memberikan hibah dengan nomor kontrak 02/LPM-UGJ/VII/2020, Guru dan Siswa kelas VI SDN II Kedungdawa Kabupaten Cirebon yang telah berbagi bagaimana proses KBM pada masa pandemi ini.

\section{DAFTAR RUJUKAN}

Awalia, I., Pamungkas, A. S., \& Alamsyah, T. P. (2019). Pengembangan Media Pembelajaran Animasi Powtoon pada Mata Pelajaran Matematika di Kelas IV SD. Kreano, Jurnal Matematika Kreatif-Inovatif. https://doi.org/10.15294/kreano.v10i1.185 34

Fitriyani, N. (2019). Pengembangan Media Pembelajaran Audio-Visual PowToon tentang Konsep Diri dalam Bimbingan Kelompok untuk Peserta Didik Sekolah Dasar. Jurnal Tunas Bangsa, 6(1), 104114.

Kurniawati, N. (2020). CREATING LOW-COST ANIMATION VIDEO USING ONLINE PLATFORM: A LEARNING MEDIA USER REVIEW. Jurnal Pendidikan Kedokteran Indonesia: The Indonesian Journal of Medical https://doi.org/10.22146/jpki.53166

Nuswantoro, D., \& Dwi Wicaksono, V. (2019). Pengembangan Media Video Animasi Powtoon Â€@Ehakanâ€ Pada Mata Pelajaran Ppkn Materi Hak Dan Kewajiban Siswa Kelas Iv Sdn Lidah Kulon Iv Surabaya. Jurnal Penelitian Pendidikan Guru Sekolah Dasar, 7(4), 3161-3170.

Oktaviani, L., Mandasari, B., \& Maharani, R. A. (2020). IMPLEMENTING POWTOON TO IMPROVE STUDENTS

INTERNATIONAL CULTURE UNDERSTANDING IN ENGLISH. 1(1), 19-25.

Pais, M. H. R., Nogués, F. P., \& Muñoz, B. R. (2017). Incorporating powtoon as a learning activity into a course on technological innovations as didactic resources for pedagogy programs. International Journal of Emerging Technologies in Learning, 12(6), 120-131. https://doi.org/10.3991/ijet.v12i06.7025

Pangestu, M. D., \& Wafa, A. A. (2018). Pengembangan multimedia interaktif powtoon pada mata pelajaran ekonomi pokok bahasan kebijakan moneter untuk siswa kelas xi ips di sma negeri 1 singosari. Jurnal Pendidikan Ekonomi.
Purnamasari, Y., Education, E., Program, S., Training, T., \& Suryakancana, U. (2013). "Teaching and Learning English: Current Trends, Issues \& Practices " POWTOON AS DIGITAL MEDIA ALTERNATIVE FOR TEACHER:

Syafitri, A., Asib, A., \& Sumardi, S. (2018). An Application of Powtoon as a Digital Medium: Enhancing Students' Pronunciation in Speaking. International Journal of Multicultural and Multireligious Understanding. https://doi.org/10.18415/ijmmu.v5i2.359

Trina, Z., Kamaruddin, T., \& Rahmani, D. (2017). Penerapan Media Animasi Audio Visual Menggunakan Software Powtoon untuk Meningkatkan hasil Belajar IPS SMP Negeri 16 Banda Aceh. 2(2), 156-169. 